\title{
FTY720-induced enhancement of autophagy protects cells from FTY720 cytotoxicity in colorectal cancer
}

\author{
JUAN LI $^{1 *}$, SHU-WEI WANG ${ }^{2 *}$, DONG-SHENG ZHANG ${ }^{1 *}$, YE SUN $^{1 *}$, \\ CHUN-YAN ZHU ${ }^{1}$, QIANG FEI ${ }^{1}$, JUN HU ${ }^{3}$, CHUAN ZHANG $^{1}$ and YUE-MING SUN ${ }^{1}$ \\ ${ }^{1}$ Department of Colorectal Surgery, The First Affiliated Hospital of Nanjing Medical University, Nanjing, Jiangsu 210029; \\ ${ }^{2}$ Department of General Surgery, Wuxi Affiliated Hospital of Nanjing University of Chinese Medicine, Wuxi; \\ ${ }^{3}$ Department of Hepatobiliary Surgery, First People's Hospital of Changzhou, Changzhou, Jiangsu 214000, P.R. China
}

Received November 29, 2015; Accepted February 1, 2016

DOI: $10.3892 /$ or.2016.4668

\begin{abstract}
FTY720, also known as fingolimod, is a widely used immunomodulator in multiple sclerosis and multiple organ transplantation. It is also an important protein phosphatase 2A (PP2A) activator. Based on this, a number of studies have recently demonstrated the cytotoxic effect of FTY720 in various cancers. Yet in colorectal cancer (CRC), the underlying mechanisms of FTY720 cytotoxicity remain less clear, especially the relationship between a drug and autophagy. We demonstrate here for the first time that FTY720 promotes the appearance of autophagic hallmarks such as autophagosome formation and light chain 3 (LC3)-II accumulation, indicating the participation of autophagy in FTY720 cytotoxicity on CRC. Moreover, inhibition of autophagy using 3-methyladenine (3-MA), a specific inhibitor of autophagy, enhanced FTY720 cytotoxicity, indicating the protective role of autophagy against the drug's own cytotoxic effect. The protective autophagy was likely affected by cancerous inhibitor of PP2A (CIP2A), an endogenous PP2A inhibitor that is closely related with poor
\end{abstract}

Correspondence to: Dr Yue-Ming Sun, Department of Colorectal Surgery, The First Affiliated Hospital of Nanjing Medical University, 300 Guangzhou Road, Nanjing, Jiangsu 210029, P.R. China E-mail: sym890207@163.com

${ }^{*}$ Contributed equally

Abbreviations: $\mathrm{PP} 2 \mathrm{~A}$, protein phosphatase $2 \mathrm{~A}$; CRC, colorectal cancer; LC3, light chain 3; 3-MA, 3-methyladenine; CIP2A, cancerous inhibitor of PP2A; PARP, poly (ADP-ribose) polymerase; RNAi, RNA interference; GFP, green fluorescent protein; siRNA, small interfering RNA; RT, reverse transcription; qPCR, quantitative PCR; CCK-8, Cell Counting Kit-8; FITC, fluroescein isothiocyanate; PBST, PBS containing 1\% Tween-20; cDNA, complementary DNA; TBST, Tris-buffered saline solution containing $0.1 \%$ Tween-20; $\mathrm{IC}_{50}$, The median inhibitory concentrations; SD, standard deviation

Key words: FTY720, colorectal cancer, autophagy, cytoprotection, drug resistance, CIP2A prognosis and drug resistance. Consequently, our data not only demonstrate a new mechanism underlying the cytotoxic effect of FTY720 in CRC, but also a new strategy for CRC treatment, especially in cases resistant to conventional chemotherapies because of high CIP2A levels.

\section{Introduction}

Colorectal cancer (CRC) is the third most common cancer, causing as many as 693,900 deaths in 2012 worldwide (1). As lifestyles have changed along with socioeconomic development, it is no surprise that risk factors such as unhealthy diet, obesity, physical inactivity, and smoking have increased CRC incidence (2). In contrast, CRC screening has led to improved awareness of self-hygiene and standardized treatments (3), decreasing the CRC mortality rate (1). Nevertheless, CRC remains the fourth and third leading cause of cancer-related death in men and women, respectively. Furthermore, numerous patients with CRC still develop recurrence or metastasis, leading to 5-year survival rates as low as $60-70 \%$ (4).

Protein phosphatase 2A (PP2A) is a major phosphoprotein phosphatase belonging to the superfamily of protein serine/ threonine phosphatases (5). It plays an important role in tumor suppression by preventing cell transformation (6). Recently, investigations based on activating PP2A activity pharmacologically in cancer have been highlighted (7). FTY720, also known as fingolimod, is an immunomodulator most widely used in multiple sclerosis and multiple organ transplantation (8-10). Structurally similar to sphingosine, it is a PP2A activator (11). Compared with traditional chemotherapies, FTY720 is less toxic and has better oral bioavailability, therefore it can be considered an alternative for cancer therapy (12), and has been widely used in various cancers. To provide better guidance for cancer treatment, the cancer inhibitory mechanisms of FTY720 require further elucidation.

In the present study, we discovered first that FTY720 promotes autophagy in CRC cell lines and that inhibition of autophagy by 3-methyladenine (3-MA), a specific autophagy inhibitor, enhanced FTY720 cytotoxicity, indicating the protective role of autophagy in FTY720 treatment of CRC. Furthermore, FTY720-induced autophagy was closely related with cancerous inhibitor of PP2A (CIP2A), an endogenous 
PP2A inhibitor. Therefore, we propose a new strategy for treating CRC through the autophagy pathway using FTY720.

\section{Materials and methods}

Cell lines and cell culture. The human CRC cell lines DLD-1 and LoVo were maintained in our laboratory. Both cell lines were cultured in Dulbecco's modified Eagle's medium (DMED; Wisent Inc., St-Bruno, Quebec, Canada) supplemented with $10 \%$ fetal bovine serum (Wisent Inc.), $100 \mathrm{U} / \mathrm{ml}$ penicillin, and $100 \mu \mathrm{g} / \mathrm{ml}$ streptomycin at $37^{\circ} \mathrm{C}$ in an incubator containing $5 \% \mathrm{CO}_{2}$.

Reagents and antibodies. FTY720 and 3-MA were purchased from Sigma-Aldrich (Sigma, St. Louis, MO, USA). FTY720 was dissolved in dimethyl sulfoxide (DMSO; Sigma) to a primary concentration of $10 \mathrm{mM}$, and 3-MA was dissolved in phosphatebuffered saline (PBS; Wisent Inc.) to a primary concentration of $100 \mathrm{mM}$. The same concentration of DMSO was used as vehicle, and did not exceed $1 \%$. The antibodies to light chain 3 (LC3)-I/II, poly(ADP-ribose) polymerase (PARP), Bcl-xL and Bcl-2 were purchased from Cell Signaling Technology (BSN; USA), and CIP2A was from Abcam (Cambridge, MA, USA).

RNA interference (RNAi) and green fluorescent protein (GFP)-LC3 transfection. Chemically synthesized scrambled RNAi oligonucleotides and small interfering RNA (siRNA) targeting human CIP2A were purchased from GenePharma (Shanghai, China). The CIP2A siRNA sequences are: 5'-GGACCCACGUUUGAUUACUTT-3' (sense) and 5'-AGUAAUCAAACGUGGGUCCTT-3' (antisense); the control siRNA sequences are: 5'-UUC UCCGAACGUGUCACGUdTdT-3' (sense) and 5'-ACGUG ACACGUUCGGAGAAdTdT-3' (antisense). The siRNA transfection was performed using Lipofectamine 2000 (Invitrogen, Carlsbad, CA, USA) according to the manufacturer's instruction. Transfection efficacy was determined by detecting CIP2A expression levels using reverse transcription (RT)-PCR and western blotting after 48-h transfection. The GFP-LC3 was a kind gift from the Department of Gastric Surgery, The First Affiliated Hospital of Nanjing Medical University. Transfection was also performed using Lipofectamine 2000, and validation of the transfection was directly observed under fluorescence microscopy.

Cell Counting Kit-8 (CCK-8) assay. Cell proliferation was measured using the CCK- 8 assay (Beyotime Institute of Biotechnology, Shanghai, China) according to the manufacturer's protocol. Cells were seeded into 96-well plates at 5000 cells/well. Each group had at least three replicates. After 24-h incubation, each group was treated with FTY720 or 3-MA for 24 and $48 \mathrm{~h}$. To assess cell viability, $10 \mu \mathrm{l} \mathrm{CCK-8}$ mixed with $90 \mu \mathrm{l}$ complete medium was added to each well and incubated at $37^{\circ} \mathrm{C}$ for $2 \mathrm{~h}$. The absorbance was measured at $450 \mathrm{~nm}$ using a microplate reader. Cell viability was determined as the percentage of absorbance of drug-treated cells to that of vehicle-treated cells.

Colony formation assay. Cells were seeded into 6-well plates at 500 cells/well in triplicate. After 24-h incubation, cells were pretreated with 3-MA $(5 \mathrm{mM})$ for $6 \mathrm{~h}$ or not treated, and then treated with FTY720 $(2.5 \mu \mathrm{M})$ or vehicle for $24 \mathrm{~h}$. Then, they were incubated in drug-free medium for another two weeks, after which the colonies that had formed were fixed with $70 \%$ methanol and stained with crystal violet, and could then be observed with the naked eye. The colony-formation ability was evaluated based on the proportion of colonies formed in the drug-treated group as compared to that in the vehicle.

Flow cytometric analysis of apoptosis. Cells $\left(2 \times 10^{5}\right)$ were seeded in 12-well plates for $24 \mathrm{~h}$, and then pretreated with $5 \mathrm{mM} 3$-MA for $6 \mathrm{~h}$ or not treated, followed by $10 \mu \mathrm{M}$ FTY720 or vehicle for $24 \mathrm{~h}$. To detect apoptosis, all cells, including apoptotic, dead, and adherent cells, were collected and resuspended in cold PBS for analysis. Apoptosis was detected using an Annexin V-FITC Apoptosis Detection kit (eBioscience, Vienna, Austria) according to the manufacturer's instructions. Data were assessed by flow cytometry (Becton-Dickinson, San Jose, CA, USA).

Cell cycle analysis. Cells $\left(4 \times 10^{5}\right)$ were seeded in 6-well plates for $24 \mathrm{~h}$, and then pretreated with $5 \mathrm{mM} \mathrm{3-MA}$ for $6 \mathrm{~h}$ or not treated, followed by $10 \mu \mathrm{M}$ FTY720 or vehicle for $24 \mathrm{~h}$. After that, cells were harvested and resuspended in cold PBS, followed by being fixed with $70 \%$ ethanol at $4{ }^{\circ} \mathrm{C}$ for $30 \mathrm{~min}$ then stored at $-20^{\circ} \mathrm{C}$ overnight. The next day, cells were centrifuged to remove ethanol and washed with PBS. After another centrifugation, PI/RNase staining buffer (BD Biosciences) were used according to the manufacturer's instructions. Data were analyzed by flow cytometry (Becton-Dickinson).

Transmission electron microscopy. Cells treated with $10 \mu \mathrm{M}$ FTY720 or vehicle were collected, washed with warm PBS, and fixed with $2.5 \%$ glutaraldehyde in $0.1 \mathrm{M}$ cacodylate buffer with $1 \%$ sucrose for $3 \mathrm{~h}$ at $4^{\circ} \mathrm{C}$. Subsequently, cells were washed three times using cacodylate buffer, then post-fixed in $1 \%$ osmium tetroxide in the same buffer for $3 \mathrm{~h}$. After another three washes in cacodylate buffer, the cells were dehydrated by an ascending concentration of ethanol at $4^{\circ} \mathrm{C}$. After infiltration with a medium compound containing Epon 812 and Spurr's resin, ultrathin sections were double-stained with uranyl acetate and lead citrate (13). The results were observed and were photographed using a JEM-1010 transmission electron microscope (JEOL, Ltd.); obtainment of the ultrathin sections and observation were performed by an experienced technologist.

Immunofluorescence assay and GFP-LC3 overexpression. DLD-1 and LoVo cells $\left(2 \times 10^{4}\right)$ were treated with $10 \mu \mathrm{M}$ FTY720 or vehicle for $24 \mathrm{~h}$, and then the cells were washed and fixed with $4 \%$ paraformaldehyde and permeabilized with $0.5 \%$ Triton X-100 in PBS for 10 min. LC3-I and LC3-II (1:200) were used as primary antibodies, and Alexa Fluor 555-labeled donkey anti-rabbit immunoglobulin G (Beyotime Institute of Biotechnology) was used as the secondary antibody to visualize LC3. To obtain better magnification, the fluorescence was observed by confocal microscopy (Zeiss, Jena, Germany) at x570 magnification. Following GFP-LC3 transfection, $2 \times 10^{4}$ cells were treated with $10 \mu \mathrm{M}$ FTY720 or vehicle for $24 \mathrm{~h}$, fixed with $4 \%$ paraformaldehyde, washed 
A

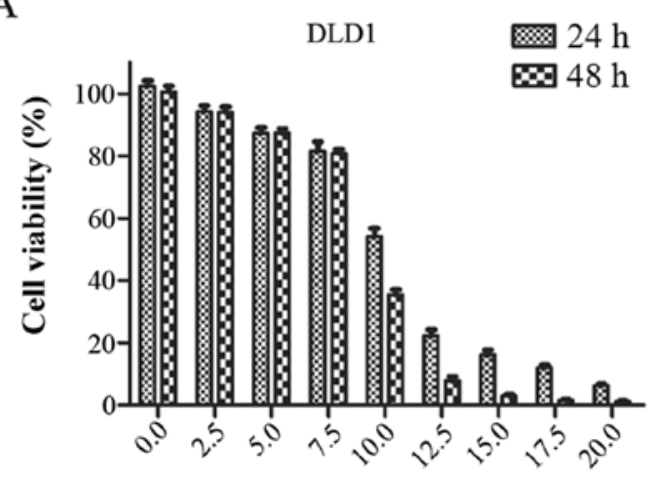

FTY720 $(\mu \mathrm{M})$

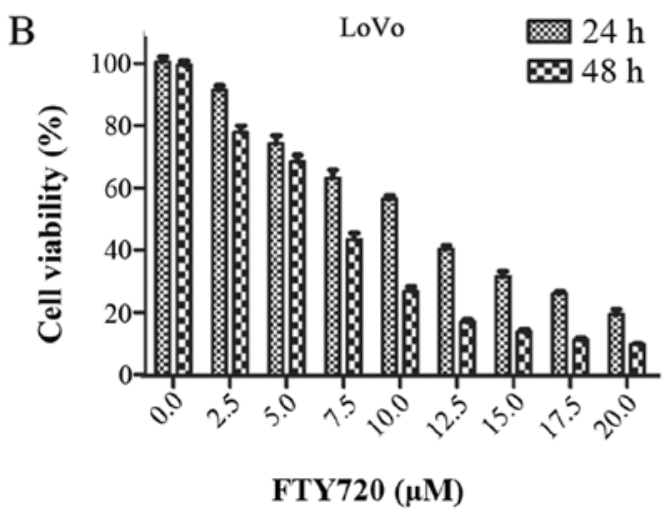

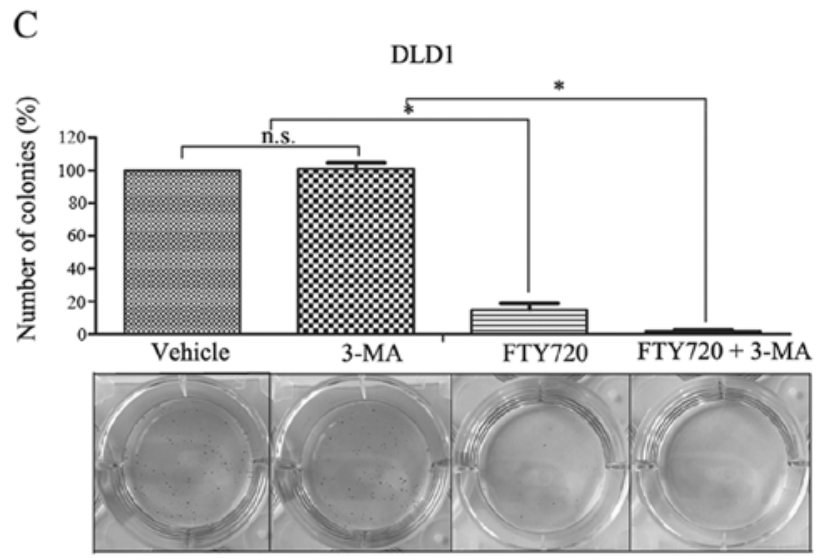

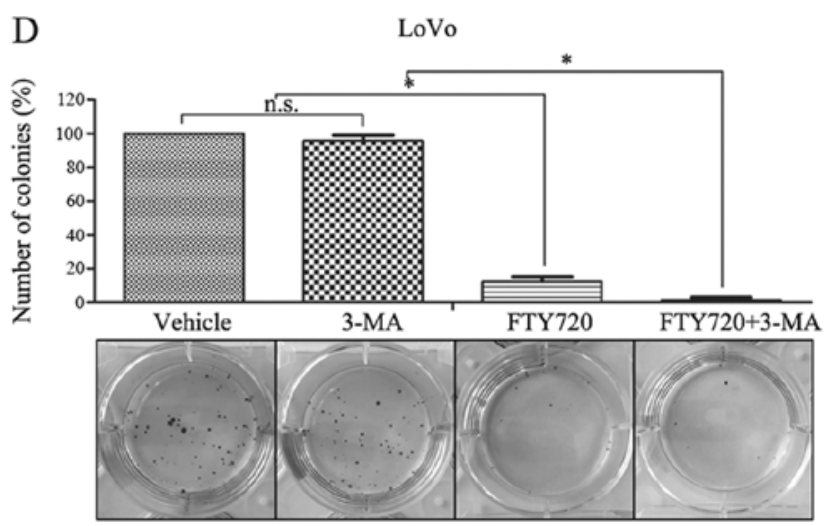

Figure 1. Cytotoxic effects of FTY720 in CRC cells, and 3-MA-pretreated cells formed less colonies. Cytotoxic effects of FTY720 in CRC cells. (A and B) Cell viability was assessed by CCK8 assay in cells treated with FTY720 at increasing concentrations for 24 and $48 \mathrm{~h}$. (C and D) Colony-forming ability of Vehicle-, 3-MA-, FTY720- and FTY720/3-MA-treated DLD1 and LoVo cells. Colony forming assay showing effects of FTY720 alone or in combination with 3-MA in DLD1 and LoVo cells. The colony formation ability was evaluated based on the proportion of colonies formed in the drug-treated group as compared to that in the vehicle. Data are means \pm SD from three independent experiments. ${ }^{*} \mathrm{P}<0.05$; n.s., not significant.

with PBS containing 1\% Tween-20 (PBST), and observed by confocal microscopy.

Quantitative real-time RT-PCR. Total RNA from the cells was extracted using TRIzol reagent (Invitrogen), and complementary DNA (cDNA) was synthesized using a PrimeScript RT reagent kit (Takara, Dalian, China) according to the manufacturer's instructions. The primers used for quantitative PCR (qPCR) are as follows: Forward, 5'-TGGCAAGATTGACCT GGGATTTGGA-3' and reverse, 5'-AGGAGTAATCAAAC GTGGGTCCTGA-3' for CIP2A; and forward, 5'-AGAAAA TCTGGCACCACACC-3' and reverse, 5'-TAGCACAGCCTG GATAGCAA-3' for $\beta$-actin. The qPCR was performed using a SYBR Green PCR kit (Roche, Indianapolis, IN, USA) in a StepOnePlus Real-time PCR System (Applied Biosystems, Foster City, CA, USA). The PCR cycling conditions were as follows: $95^{\circ} \mathrm{C}$ for $30 \mathrm{sec}, 40$ cycles of $95^{\circ} \mathrm{C}$ for $5 \mathrm{sec}, 60^{\circ} \mathrm{C}$ for $31 \mathrm{sec}$; for the dissociation stage: $95^{\circ} \mathrm{C}$ for $15 \mathrm{sec}, 60^{\circ} \mathrm{C}$ for $1 \mathrm{~min}$, and $95^{\circ} \mathrm{C}$ for $15 \mathrm{sec}$. Each sample was analyzed thrice. $\Delta \Delta \mathrm{Ct}$ method was used for analysis.

Western blot analysis. Cells were lysed using radioimmunoprecipitation assay buffer (PARP; Beyotime Institute of Biotechnology), and equivalent amounts of protein were separated by sodium dodecyl sulfate-polyacrylamide gel electrophoresis and subsequently transferred to polyvinylidene fluoride membranes (Millipore, Bedford, MA, USA). The membranes were blocked in 5\% non-fat milk dissolved in Trisbuffered saline solution containing $0.1 \%$ Tween-20 (TBST) for 2-4 $\mathrm{h}$ at room temperature, and then incubated with antibodies specific for LC3, CIP2A, and $\beta$-actin $(1: 1000)$ at $4^{\circ} \mathrm{C}$ overnight. After washing three times with TBST, the membranes were incubated with horseradish peroxidase-conjugated secondary antibody (1:1000; Beijing Biosynthesis Biotechnology) at room temperature for $2 \mathrm{~h}$. After three TBST washes, bound proteins were visualized using ECL Plus (Millipore) by a Bio-Imaging System. $\beta$-actin was used as the internal loading control.

Statistical analysis. Statistical analysis was performed using Statistical Program for Social Sciences (SPSS) 20.0 software (IBM, SPSS Inc., Chicago, IL, USA). One-way analysis of variance was used for comparison between groups. $\mathrm{P}<0.05$ indicated statistically significant differences.

\section{Results}

Effect of FTY720 on CRC cell viability. To evaluate FTY720 cytotoxicity in vitro, we treated two randomly selected CRC cell lines: DLD-1 and LoVo, with or without different concentrations of FTY720. After 24- and 48-h drug exposure, we detected the cell proliferation capacity using the CCK-8 assay. As shown in Fig. 1A and B, the viability of both cell lines decreased as the drug concentration increased. In the same way, under specific drug concentrations, 48-h exposure was 
A

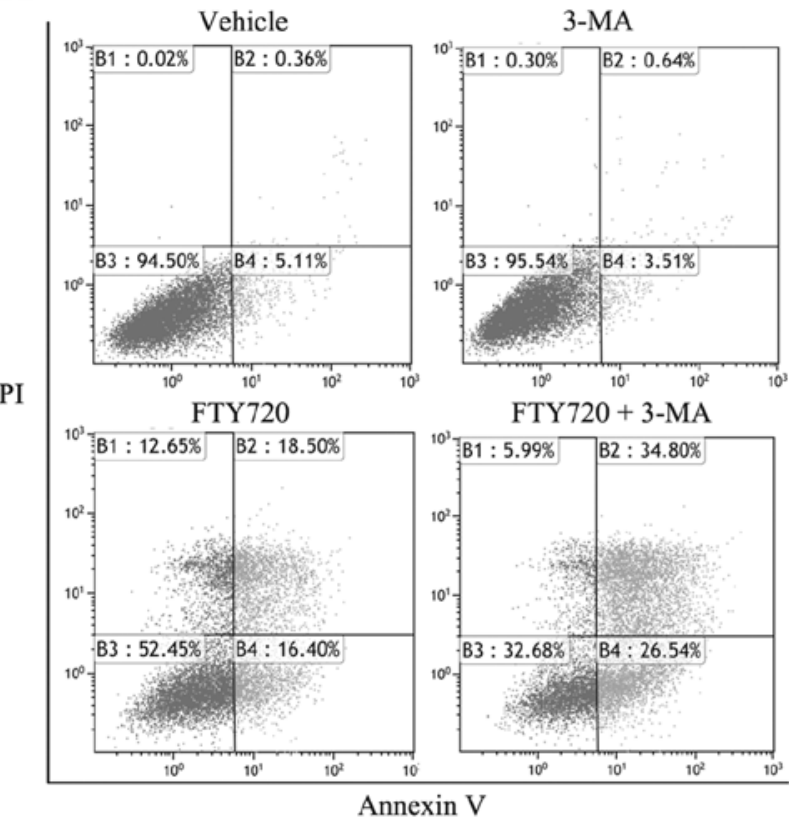

$\mathrm{B}$

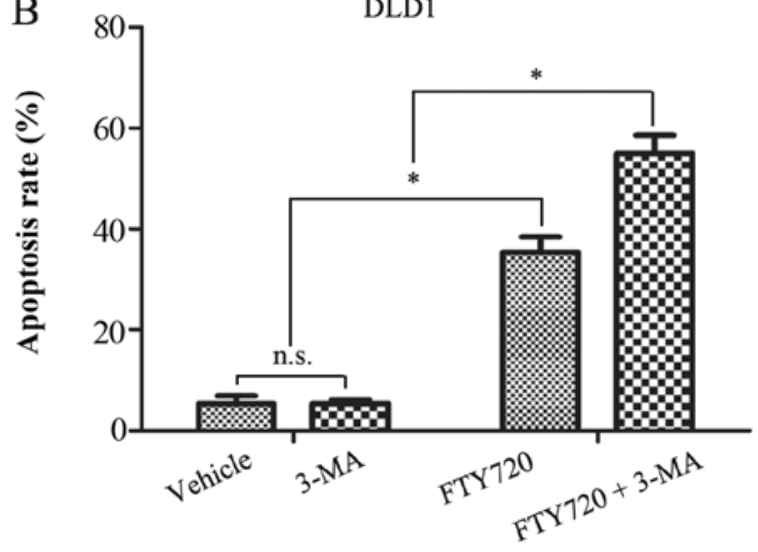

E

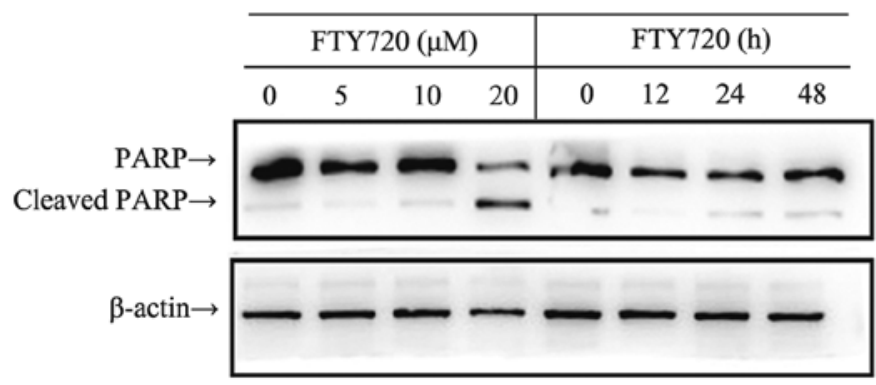

$\mathrm{C}$

LoVo

PI
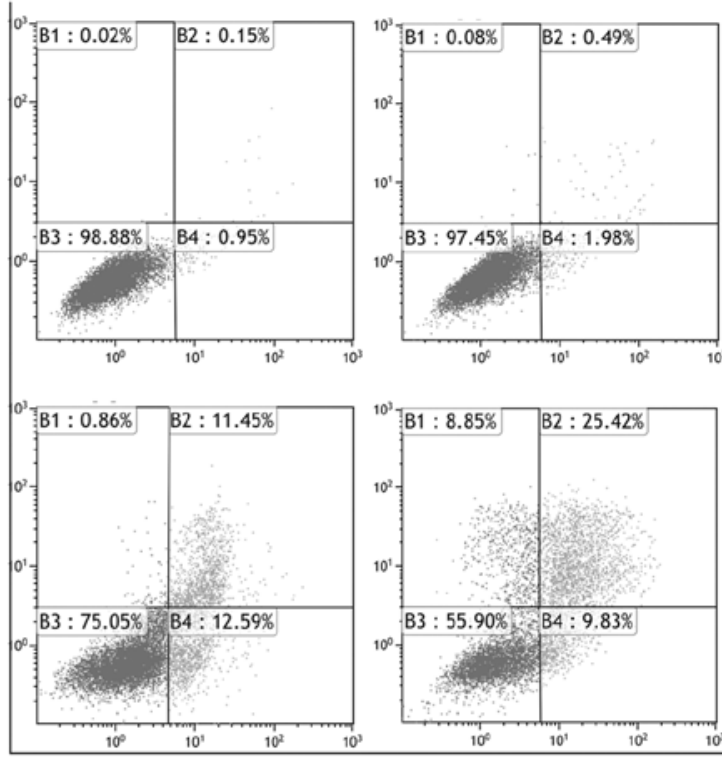

Annexin V

$\mathrm{D}$

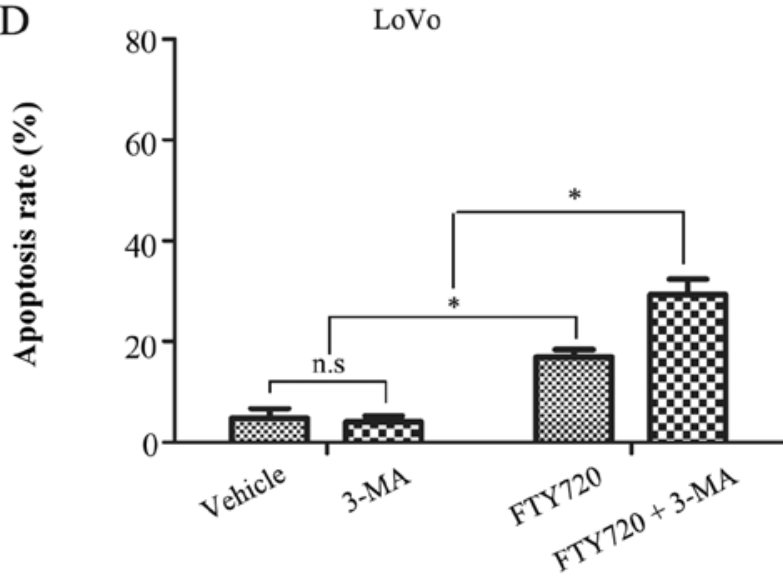

LoVo

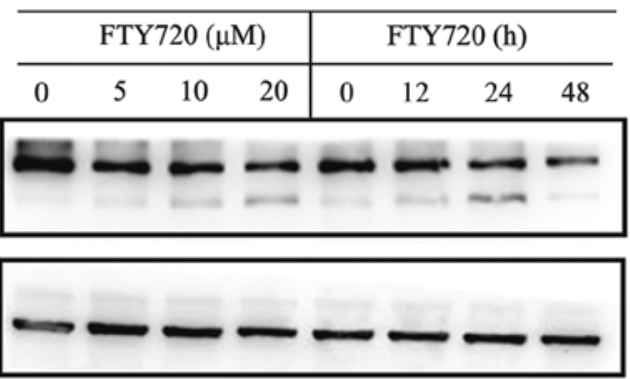

Figure 2. FTY720 induces apoptosis in CRC cell lines, and 3-MA-pretreated cells presented a higher percentage of apoptosis. DLD1 (A and B) and LoVo (C and D) cells were treated with FTY720 or FTY720 plus 5 mM 3-MA, and apoptosis was detected using flow cytometry. "P<0.05; n.s., not significant. (E) Cells were treated with or without 5,10 , or $20 \mu \mathrm{M}$ FTY720 for $12 \mathrm{~h}$ or with the same concentration $(10 \mu \mathrm{M})$ of FTY720 for different durations $(12,24$, $48 \mathrm{~h}$ ), lysed and immunoblotted with the PARP antibody.

more effective than 24-h exposure. The median inhibitory concentrations $\left(\mathrm{IC}_{50}\right)$ for each cell line are shown in Table $\mathrm{I}$. To assess the long-term effect of FTY720, we performed a colony formation assay. Consistent with the CCK-8 assay, the results showed that 24-h pretreatment with FTY720 distinctly decreased the number of colonies formed as compared to the controls for both cell lines (Fig. 1C and D).
FTY720 induces apoptosis in CRC cell lines. To further evaluate the effect of FTY720 on cell physiological function, we assessed its apoptotic effect on DLD-1 and LoVo cells, using flow cytometry to analyze the apoptotic effect. As expected, after 24-h exposure to $10 \mu \mathrm{M}$ FTY720, there were markedly elevated percentages of positive-staining DLD-1 and LoVo cells as compared with the vehicle (Fig. 2A-D). In 


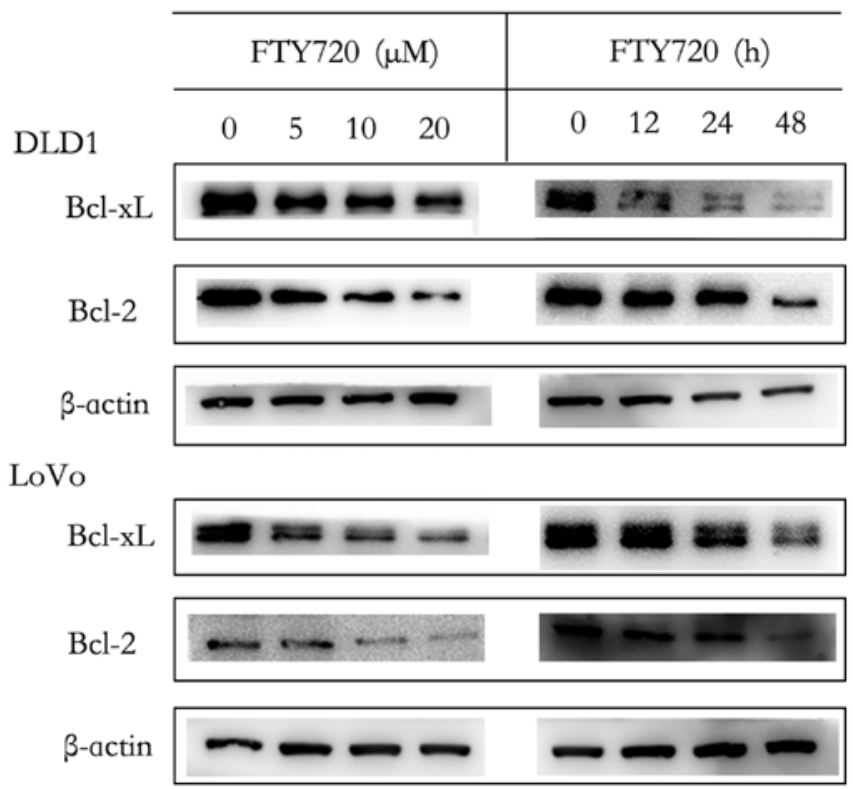

Figure 3. FTY720-induces decreased Bcl-xL and Bcl-2. Cells were treated with or without 5,10 , or $20 \mu \mathrm{M}$ FTY720 for $12 \mathrm{~h}$ or with the same concentration $(10 \mu \mathrm{M})$ of FTY720 for different durations $(12,24,48 \mathrm{~h})$, lysed and immunoblotted with the Bcl-xL and Bcl-2 antibodies.

addition, $\mathrm{Bcl}-\mathrm{xL}$ and $\mathrm{Bcl}-2$ are two anti-apoptotic members of the Bcl-2 family (14). So when apoptosis was induced, both of them decreased. Furthermore, PARP is a substrate of caspase 3. Therefore, it is reasonable that the presence or absence of cleaved PARP would reflect whether FTY720 induced apoptosis. We treated DLD-1 and LoVo cells with or without 5,10 , or $20 \mu \mathrm{M}$ FTY720 for $12 \mathrm{~h}$, or with the same concentration (10 $\mu \mathrm{M}$ FTY720) for different durations (12, 24, 48 h). Western blotting showed that FTY720-induced Bcl-xL
Table I. IC $_{50}$ values of FTY720 in DLD1 and LoVo cells.

\begin{tabular}{lcc}
\hline & \multicolumn{2}{c}{$\mathrm{IC}_{50}(\mu \mathrm{M})$} \\
\cline { 2 - 3 } Cell lines & $24 \mathrm{~h}$ & $48 \mathrm{~h}$ \\
\hline DLD1 & 10.05435 & 7.84012 \\
LoVo & 10.23060 & 6.94962
\end{tabular}

$\mathrm{IC}_{50}$ values for each cell line were calculated by using CompuSyn software as previously described (40).

and Bcl-2 decrease (Fig. 3) and PARP cleavage (Fig. 2E) were concentration- and time-dependent, further confirming the induction of apoptosis and cell death.

FTY720 arrests CRC cells in the G0/G1 phase. To further elucidate the effect of FTY720 on the cell cycle phases, we performed flow cytometric analysis of the cell cycle. As shown in Fig. 4, both DLD-1 and LoVo cells performed a significantly increased proportion of G0/G1 phase, followed by a sharp decrease of G2/M phase proportion after FTY720 treatment. These data suggested that FTY720 arrests GC cells in the G0/G1 phase and this result was consistent with a previous study on cholangiocarcinoma (15).

FTY720 induces autophagy in CRC cells. Besides apoptosis, autophagy is another classic form of programmed cell death (16). Autophagy participates in the process of FTY720 cytotoxicity in ovarian cancer and some hematological malignancies $(17,18)$. However, in the process of FTY720 treatment in CRC, the involvement of autophagy requires further elucidation. To this end, we first used the most traditional method, transmission
A

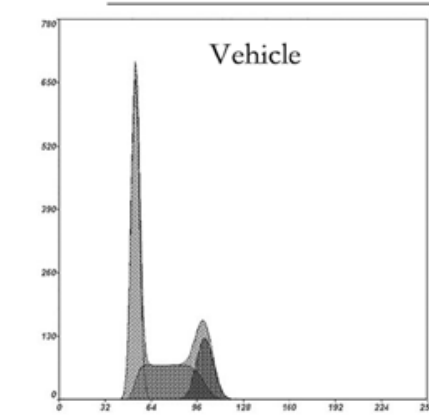

$\mathrm{C}$

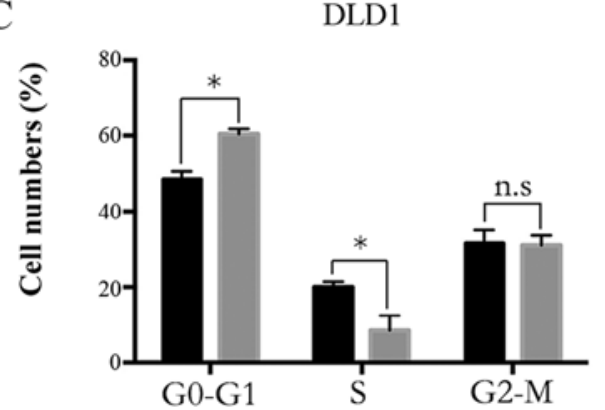

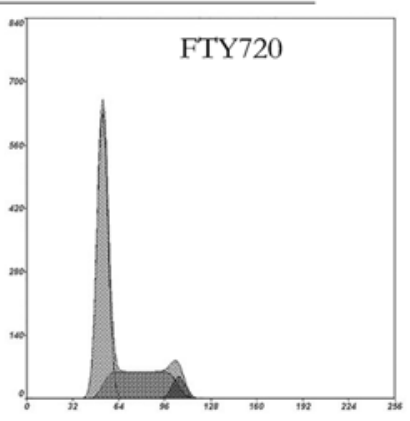

Vehicle

FTY720
B LoVo
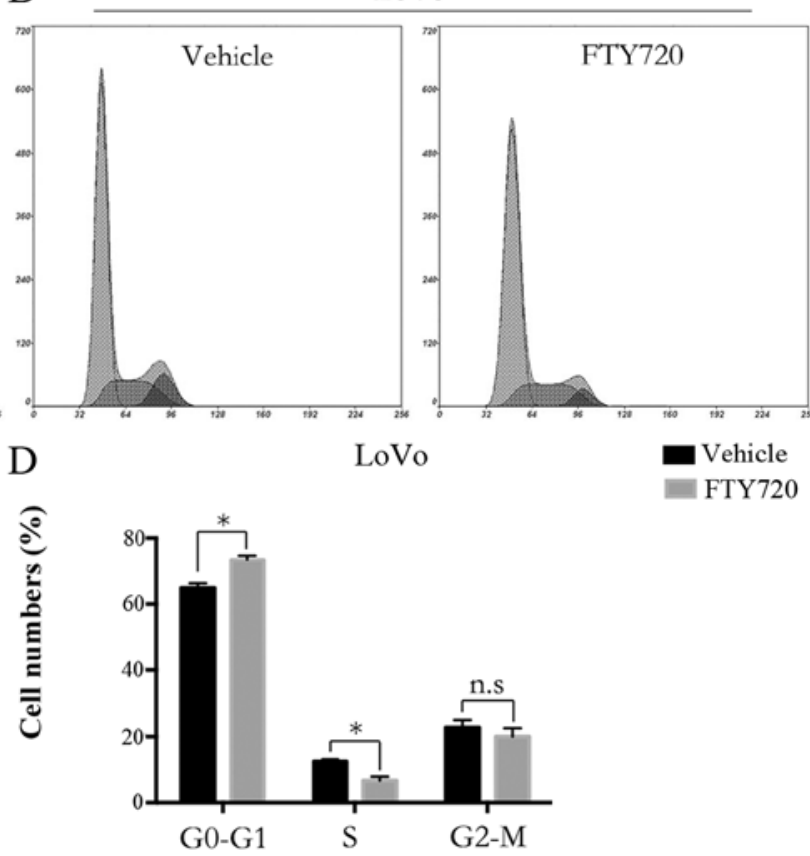

Figure 4. FTY720 arrests CRC cells in the G0/G1 phase. DLD1 (A and C) and LoVo (B and D) cells were treated with or without FTY720, and cell cycle was detected using flow cytometry. ${ }^{*} \mathrm{P}<0.05$; n.s., not significant. 

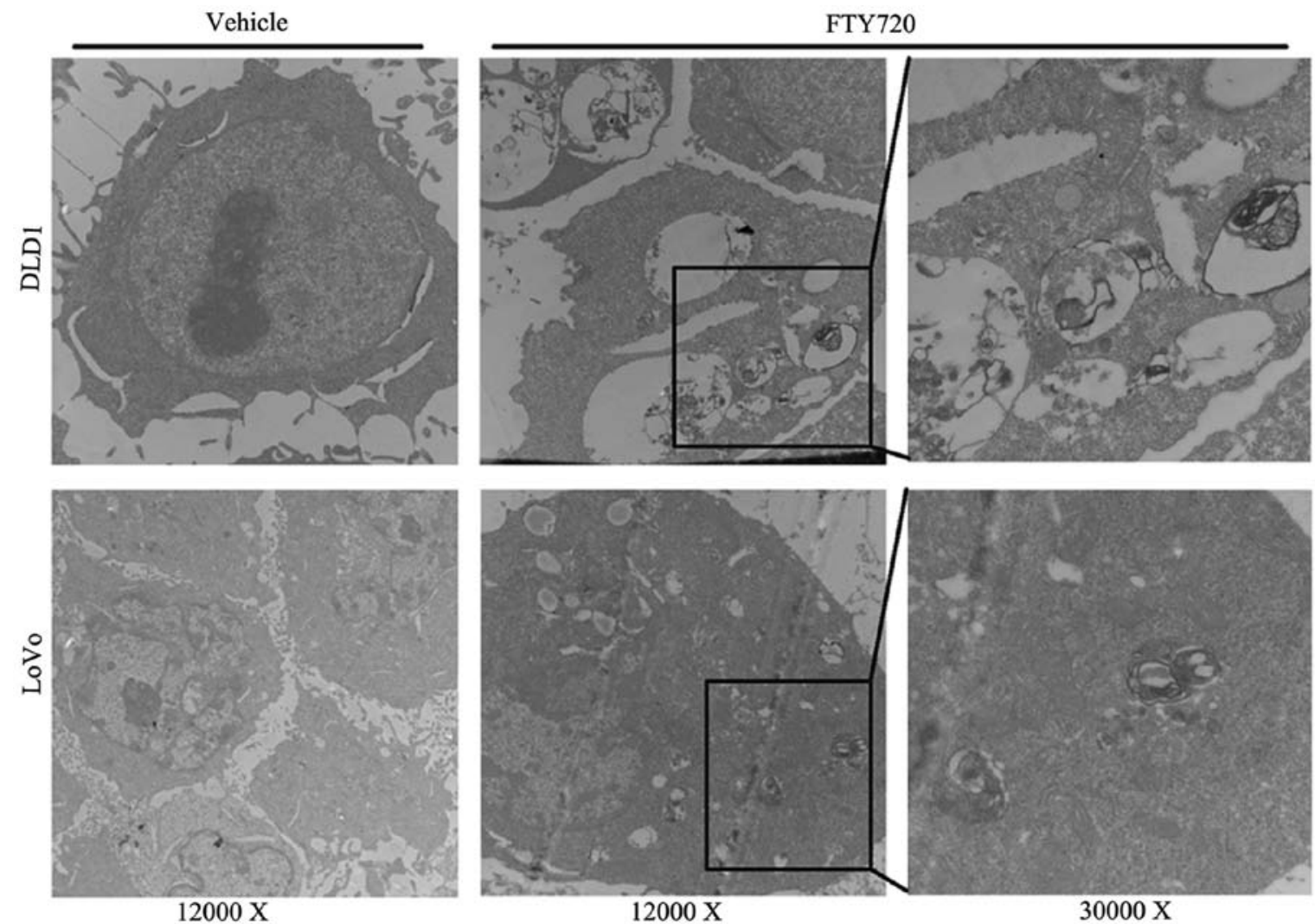

Figure 5. FTY720 induces typical autophagosome formation in CRC cells. FTY720 induces autophagy in CRC cells. Representative transmission electron microscopic images depict ultrastructures of autophagy in DLD1 and LoVo cells treated with or without FTY720 (10 $\mu \mathrm{M})$ for $24 \mathrm{~h}$.

electron microscopy, to analyze the ultrastructural morphological changes in DLD-1 and LoVo cells after 24-h FTY720 $(10 \mu \mathrm{M})$ treatment. As shown in Fig. 5, FTY720-treated cells presented typical autophagosomes with characteristics such as double-membrane structure containing undigested cytoplasm or organelles (19). Yet, few autophagosomes were observed in the vehicle-treated cells. The ultrastructural morphological changes indicated the participation of autophagy in FTY720 treatment in CRC.

LC3 is a well-known, reliable indicator of autophagy. During autophagy, the diffusely distributed endogenous cytoplasmic LC3 will convert to punctate structures (19). To verify the transformation, we performed assays observed under confocal microscopy. Using specific antibodies to cause fluorescence emission, we observed that after 24-h FTY720 $(10 \mu \mathrm{M})$ treatment, the proportion of cells forming punctate LC3 was significantly increased as compared with the vehicle (Fig. 6A and B). To confirm this effect, we overexpressed GFP-LC3 in both cell lines. Similar to the expression patterns of endogenous LC3 after FTY720 treatment, there were significantly increased GFP-LC3-transfected DLD-1 and LoVo cells with punctate fluorescence (Fig. 6C and D).

There are two forms of LC3: LC3-I and LC3-II. When autophagy is promoted, LC3-I converts to LC3-II (20). This conversion is an indicator of autophagy (21), and it can be detected by western blotting. As shown in Fig. 6E, DLD-1 and LoVo cells treated with or without 5,10 , or $20 \mu \mathrm{M}$ FTY720 for $12 \mathrm{~h}$ or with the same concentration $(10 \mu \mathrm{M})$ of FTY720 for different durations $(12,24,48 \mathrm{~h})$ showed concentration- and time-dependent increased LC3-II expression levels, indicating that autophagy induced by FTY720 in CRC is concentrationand time-dependent.

Autophagy plays a protective role in FTY720-induced cell death in CRC. As stated above, autophagy is also involved in FTY720 cytotoxicity in ovarian cancer cells. Zhang et al demonstrated that, other than a cytotoxic effect, autophagy has a protective effect (18). Yet, the role of autophagy in FTY720 cytotoxicity in CRC requires further study. To address this, we used the autophagy inhibitor 3-MA to perform a series of experiments. We pretreated DLD-1 and LoVo cells with 3-MA (5 mM) for $6 \mathrm{~h}$, followed by FTY720 $(10 \mu \mathrm{M})$ or vehicle treatment for another $24 \mathrm{~h}$. The CCK-8 assay showed that 3-MA enhanced FTY720-induced cytotoxicity (Fig. 7A and B). Similarly, we performed a colony formation assay using similar treatments (FTY720 concentration was decreased to $2.5 \mu \mathrm{M}$ ). Consistently, 3-MA-pretreated cells had weaker colony-formation capacity following FTY720 treatment as compared to vehicle-treated cells (Fig. 1C and D). In the same vein, we observed apoptosis in a higher percentage of 3-MA-pretreated cells after FTY720 treatment (Fig. 2A-D). These results all indicate the protective effect of autophagy on FTY720 cytotoxicity in CRC. Moreover, as to cell cycle, in 3-MA pretreated cells, the proportion of G0/ G1 phase was not apparently affected. However, different from the results of cell viability and apoptosis, the proportion of G0/G1 phase in 3-MA pretreated cells was not markedly increased compared with that with FTY720 alone (data not shown), indicating that FTY720 induced G0/G1 arrest was not dependent on autophagy. 
A
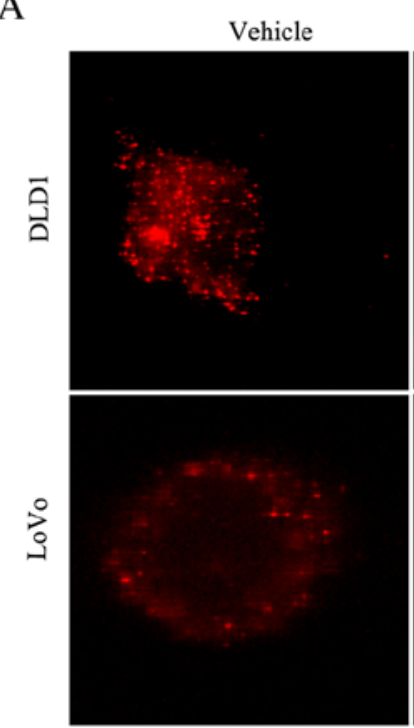

B

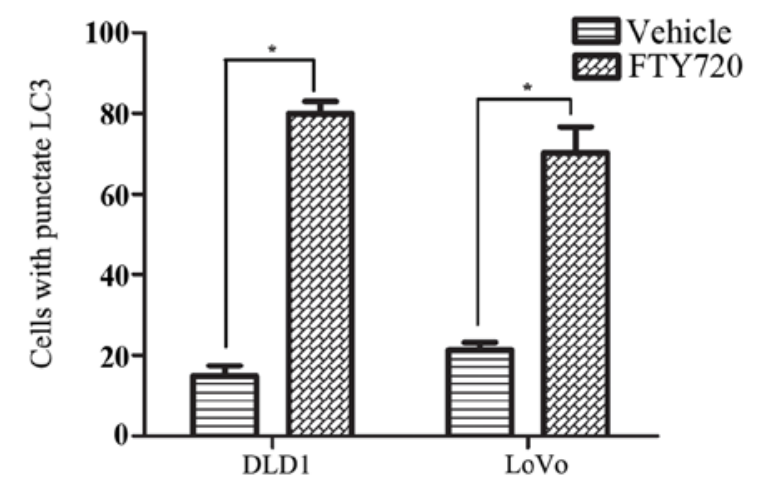

E
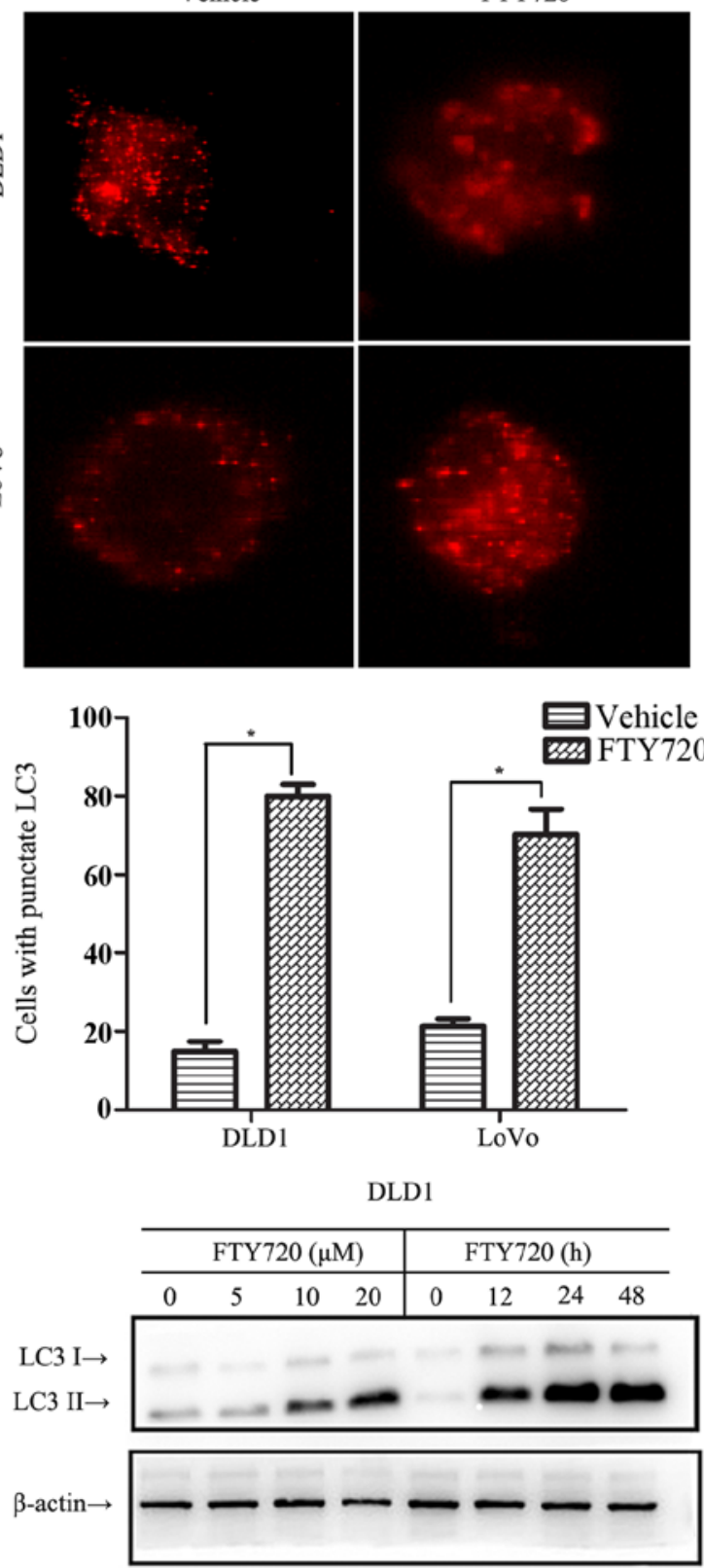

$\mathrm{C}$
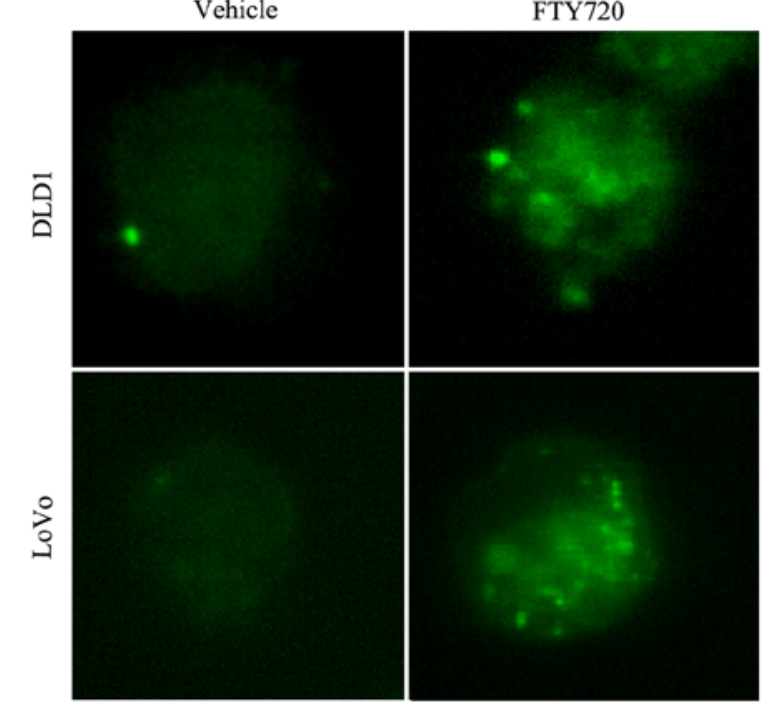

$\mathrm{D}$

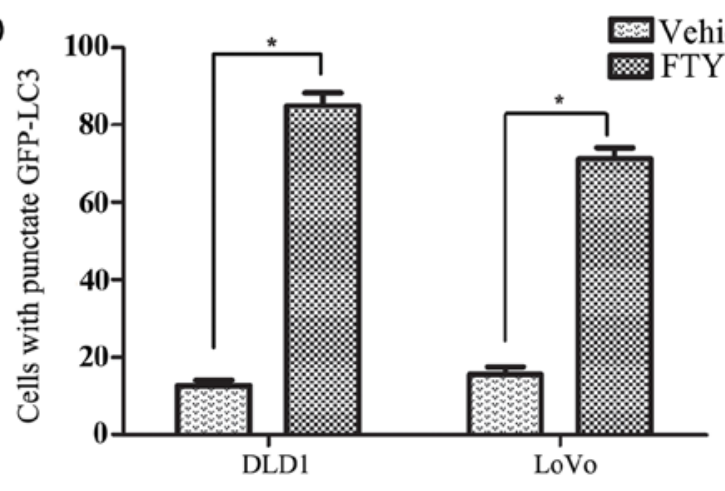

LoVo

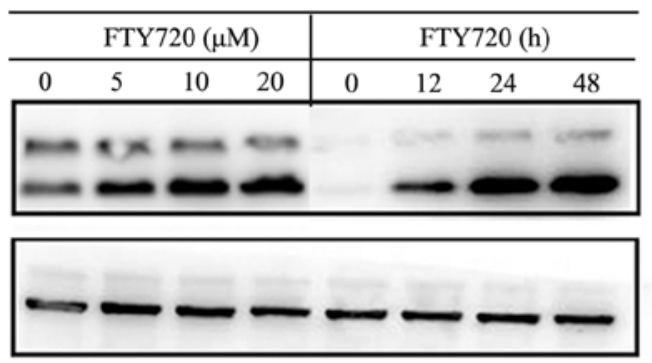

Figure 6. FTY720 induces formation of punctate LC3 and GFP-LC3, and accumulation of LC3-II. (A) Cells were treated for $24 \mathrm{~h}$ with vehicle or FTY720 $(10 \mu \mathrm{M})$. Then using specific antibodies to cause fluorescence emission. Representative images of punctate LC3 formation are shown as photographed by confocal microscopy. (B) The percentage of cells presenting typical LC3 puncta. " $\mathrm{P}<0.05$; n.s., not significant. (C) Cells were transfected with GFP-LC3, treated with vehicle or FTY720 $(10 \mu \mathrm{M})$ for $24 \mathrm{~h}$. Representative images of punctate of GFP-LC3 formation are shown as photographed by confocal microscopy. (D) The percentage of cells presenting typical GFP-LC3 puncta. "P<0.05; n.s., not significant. (E) Cells were treated with or without 5, 10, or $20 \mu \mathrm{M}$ FTY720 for $12 \mathrm{~h}$ or with the same concentration $(10 \mu \mathrm{M})$ of FTY720 for different durations $(12,24,48 \mathrm{~h})$, lysed and immunoblotted with the LC3 antibody.

Inhibition of CIP2A is associated with FTY720-induced autophagy in CRC. CIP2A is an endogenous inhibitor of PP2A, Cristobal et al showed that CIP2A is overexpressed in both CRC cell lines and cancer tissues as compared with normal controls and that FTY720 suppresses CIP2A expression at protein level (22). Moreover, another PP2A activator, bortezomib, induces autophagy by the CIP2A-PP2A-Akt4EBP1 signaling pathway in hepatocellular carcinoma (23). Consequently, it is reasonable to assume that CIP2A is associated with FTY720-induced autophagy in CRC. To validate this assumption, we used siRNA to interfere with CIP2A expression. The interference efficiency is shown in Fig. 8A-C.
Consistent with the previous study, FTY720 decreased the expression level of CIP2A in control-RNAi cells (Fig. 8C). However, CIP2A level of CIP2A-RNAi cells did not change after FTY720 treatment, possibly because after interference the CIP2A was at a relative low level. Following FTY720 treatment for the same concentration and duration, the CIP2ARNAi cells expressed higher LC3-II levels compared with that in control-RNAi cells, validating the participation of CIP2A in FTY720 induction of autophagy in CRC. Noteworthy, after FTY720 treatment, without a decrease in CIP2A level in CIP2A-RNAi cells, LC3-II levels still increased, indicating the participation of CIP2A is only partial. 

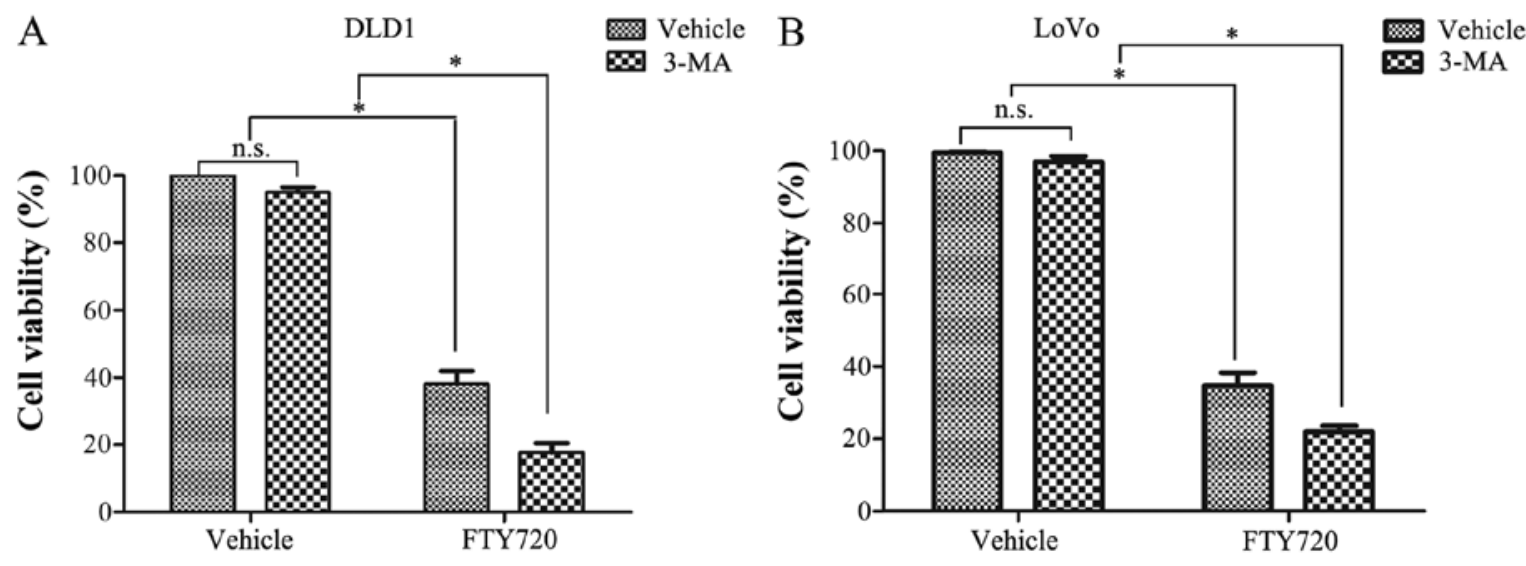

Figure 7. 3-MA enhanced FTY720-induced cytotoxicity. DLD1 (A) and LoVo (B) cells were treated with 3-MA (5 mM) for $6 \mathrm{~h}$, followed by FTY720 (10 $\mu$ M) or Vehicle treatment for another $24 \mathrm{~h}$, then cell viability was assessed by CCK8 assay. ${ }^{*} \mathrm{P}<0.05$; n.s., not significant.
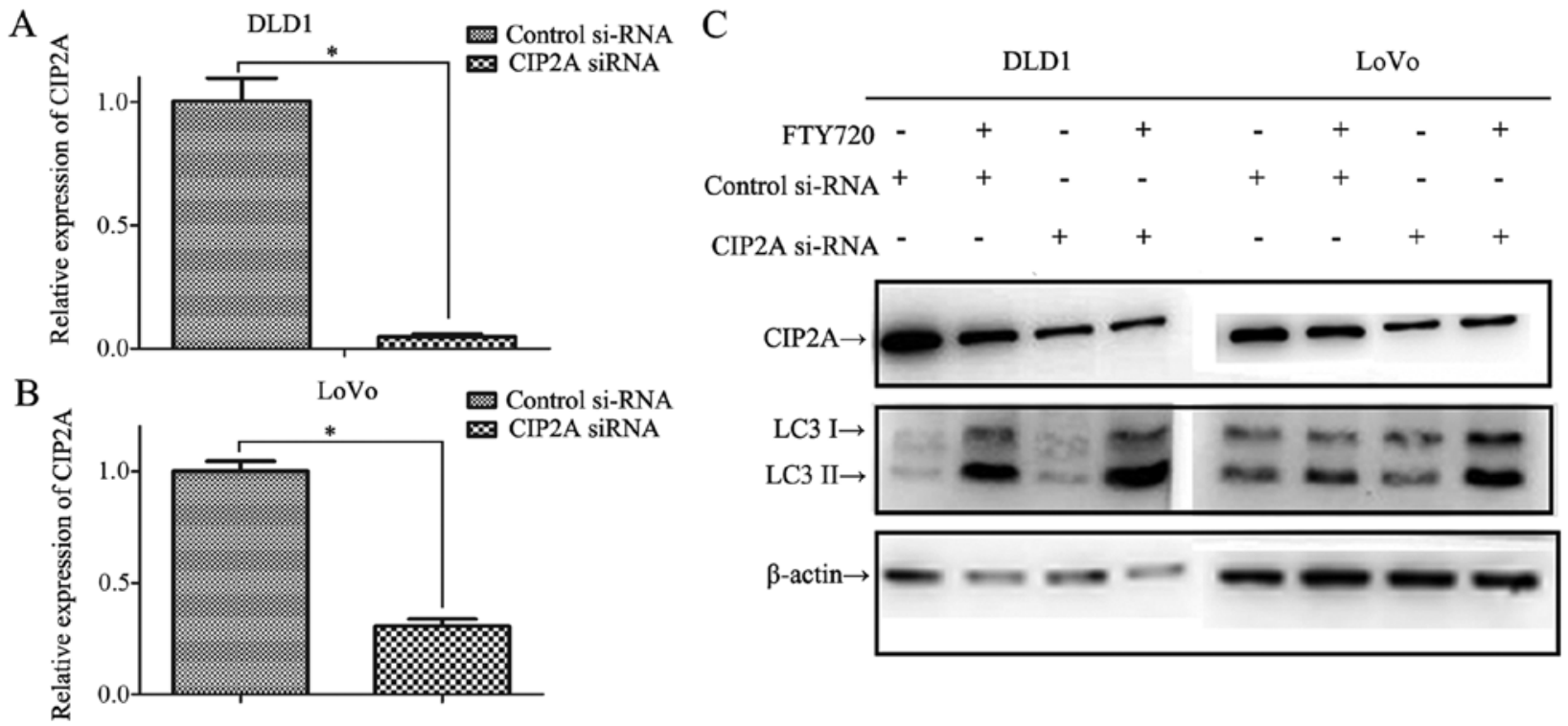

Figure 8. CIP2A si-RNA transfection and target validation of CIP2A participation in FTY720 inducd autophagy in CRC. The relative expression of CIP2A was measured in DLD1 (A) and LoVo (B) cells after transfection with conontrol si-RNA or CIP2A si-RNA. The relative CIP2A level was calculated by $2^{-\Delta \Lambda C T}$ where $\Delta \mathrm{C}_{\mathrm{T}}=\mathrm{C}_{\mathrm{T}}(\mathrm{CIP} 2 \mathrm{~A})-\mathrm{C}_{\mathrm{T}}\left(\beta\right.$-actin) and $\Delta \Delta \mathrm{C}_{\mathrm{T}}=\Delta \mathrm{C}_{\mathrm{T}}\left(\mathrm{CIP} 2 \mathrm{~A}\right.$ RNAi cell) $-\Delta \mathrm{C}_{\mathrm{T}}$ (control RNAi cell ). ${ }^{*} \mathrm{P}<0.05 ;$ n.s., not significant. (C) Cells were transfected with control si-RNA or CIP2A si-RNA, then treated with FTY720 $(10 \mu \mathrm{M})$ for $24 \mathrm{~h}$, after that, cells were lysed and immunoblotted with the indicated antibodies.

\section{Discussion}

With relatively non-toxic specificity and high oral bioavailability (12), FTY720 has been explored in vitro in various cancers, including hepatocellular carcinoma (24), acute myeloid leukemia (25), breast cancer (26), and prostate cancer (27). In cancer therapy, the drug is best known as a PP2A activator (6), while its other mechanisms of action are comparatively less well known. In the present study, we discovered first that FTY720 promotes autophagy in CRC cell lines and that inhibiting autophagy using 3-MA, a nonspecific autophagy inhibitor, enhanced FTY720 efficacy, indicating the protective role of autophagy in FTY720 cytotoxicity for CRC. Furthermore, FTY720-induced autophagy was closely related with CIP2A, an endogenous PP2A inhibitor.

In our study, we first tested the effect of different drug concentrations and incubation durations on the viability of DLD-1 and LoVo cells via the CCK- 8 assay to determine the appropriate drug concentration for subsequent experiments. The results showed that the effect of FTY720 on cells was concentration- and time-dependent. Moreover, the $\mathrm{IC}_{50}$ data we determined for each cell line were in accordance with that for ovarian cancer (18) and some leukemias (28). The significance of the $\mathrm{IC}_{50}$ of FTY720 not only provides an index for further investigation but also offers an important reference for further application to clinical trials. Of note, in the colony formation experiment, the FTY720 concentration that had partially inhibited cells in the CCK-8 assay led to whole cell death. The results are similar to a previous study on ovarian cancer, in which it was explained that the sensitivity of cells to FTY720 is related to cell density (18). Noteworthy, the drug sensitivity also differed when we treated the same number of cells seeded at different times or treated different numbers of cells seeded at the same time with FTY720 (data not shown), validating the influence of cell density on drug sensitivity. Our $\mathrm{IC}_{50}$ values were tested under $80 \%$ cell density. Similarly, the 
proportion of apoptotic cells induced by the indicated drug concentration was not entirely consistent with the CCK-8 results, indicating that it might also have been affected by cell density.

There are two classic self-destructive cell processes: apoptosis and autophagy (16). Herein, we confirm that FTY720 markedly increases the proportion of apoptotic DLD-1 and LoVo cells, decreases expression levels of anti-apoptotic Bcl-xL and Bcl-2, and induces the expression of cleaved PARP, the active form of the caspase- 3 substrate. Combined with the findings of a previous study (22), we note that FTY720-induced apoptosis is caspase-dependent. Furthermore, we confirmed first that FTY720 induces time- and dose-dependent autophagy in DLD-1 and LoVo cells. The validation of autophagy was performed via several classic experiments. The formation of autophagosomes, characterized by a double-membrane structure containing undigested cytoplasm or organelles, is the gold standard for autophagy; autophagosomes are ultrastructural and should be observed under transmission electron microscopy. However, observer subjectivity can influence the decision on the presence of autophagy. Therefore, we next detected the expression pattern and level of the microtubule-associated protein LC3, a well-known indicator of autophagy. There are two forms of LC3: LC3-I and LC3-II; the initial form of LC3 is LC3-I, which is distributed in the cytoplasm. Endogenous LC3 or GFP-LC3 visualized under fluorescence microscopy is observed as diffuse fluorescence. Otherwise, when autophagy is promoted, LC3-I is converted to LC3-II, and the latter associates with the autophagosome membranes, and then endogenous LC3 or GFP-LC3 is visualized as punctate fluorescence. The conversion of LC3-I to LC3-II can also be quantitatively and qualitatively detected by western blotting (19).

In our study, we observed the conversion in both endogenous LC3 and GFP-LC3, and the ability of FTY720 to promote autophagy was evaluated based on the proportion of cells that formed obvious puncta. Likewise, what defines 'obvious' is also subjective. Then, as a supplement, we performed western blotting to detect two forms of LC3 expression. However, how to interpret LC3 western blot data is indeed a great controversy (29), our results showed an expression level of LC3-I that was consistent with the LC3-II expression level. The reason may be that the relationship between LC3-I and LC3-II is not always 'precursor and product', because the conversion of the former to the latter often depends on the cell line, tissue and methods used to induce autophagy (30). As to 'methods used to induce autophagy', here we used FTY720. Similarly, in ovarian cancer, FTY720 also induced a pattern that LC3-I was consistent with LC3-II (18). Moreover, at present, levels of LC3-II normalized to actin, but not ratio between LC3-II and LC3-I, is regarded as the standard to evaluate autophagy in western blot analysis (31). The above assays all provided compelling evidence for the participation of autophagy in FTY720 cytotoxicity on CRC cells.

In apoptosis a cell commits suicide (32), yet autophagy can be cytotoxic or cytoprotective in cancer $(33,34)$. In most cases, apoptosis and autophagy are mutually exclusive, and in some cases the phenotype is mixed (35). Therefore, regarding the effect of FTY720 on CRC, whether autophagy functions as a killer or a promoter, or even whether autophagy and apoptosis have a synergistic or antagonistic effect requires further investigation. To solve this problem, we pretreated cells with 3-MA, an autophagy inhibitor (36). Consequently, the cytotoxicity of FTY720 was enhanced, indicating the protective role of autophagy, and like in most cases, the interaction between apoptosis and autophagy is antagonistic. Nevertheless, starkly different from previous studies, FTY720 induced not only caspase-dependent apoptosis, but also protective autophagy. However, FTY720 only promotes either caspase-dependent apoptosis or autophagy in ovarian cancer, breast cancer, and hepatocellular carcinoma (18). As for the protective role of autophagy in FTY720 cytotoxicity in CRC, it is highly likely that autophagy can be an important factor for FTY720 resistance in CRC treatment. Therefore, eliminating the impact of this aspect is essential, and we subsequently explored the mechanisms that may induce autophagy in this process.

FTY720 is a PP2A-activating drug. In this regard, we used CIP2A, an endogenous PP2A inhibitor, overexpressing it in all tested CRC cell lines and most cancer tissues as compared with the normal control. Moreover, FTY720 decreases CIP2A at protein level (10). Furthermore, bortezomib, another PP2A activator, induces autophagy through the CIP2A-PP2A-Akt4EBP1 signaling pathway in hepatocellular carcinoma (11). Consequently, we assumed that FTY720 induces autophagy by acting on CIP2A. As expected, siRNA interference of CIP2A expression markedly increased the level of LC3-II. However, without FTY720 treatment, the RNAi cells did not exhibit LC3 level alteration as compared with the negative control, suggesting CIP2A per se does not affect autophagy. The participation of CIP2A in autophagy is established based on the function of FTY720, in this process, CIP2A functions as an autophagy inhibitor. Interestingly, CIP2A is frequently reported as being overexpressed in CRC (37). Moreover, it indicates poor prognosis and is closely related with resistance to traditional chemotherapies $(38,39)$. Yet, as an inhibitor of protective autophagy, high CIP2A expression can enhance CRC cell sensitivity to FTY720. This holds promise for patients with CRC who have high CIP2A expression and low sensitivity to traditional chemotherapies. With regard to these patients, FTY720 can not only offer satisfactory curative effects, but also sensitizes them to other chemotherapies by decreasing CIP2A expression.

In conclusion, FTY720 has a significant cytotoxic effect on CRC. However, protective autophagy is a risk factor for FTY720 resistance. Yet, CIP2A, which is highly expressed and closely related to drug resistance, can block FTY720-induced autophagy so that it improves FTY720 sensitivity. This provides a new strategy for treating $\mathrm{CRC}$, especially in cases resistant to conventional chemotherapies because of high CIP2A levels.

\section{Acknowledgements}

This study was supported by a grant from the Fund of Department of Health of the Jiangsu Province, China.

\section{References}

1. Torre LA, Bray F, Siegel RL, Ferlay J, Lortet-Tieulent J and Jemal A: Global cancer statistics, 2012. CA Cancer J Clin 65: 87-108, 2015.

2. Center MM, Jemal A, Smith RA and Ward E: Worldwide variations in colorectal cancer. CA Cancer J Clin 59: 366-378, 2009. 
3. Edwards BK, Ward E, Kohler BA, Eheman C, Zauber AG, Anderson RN, Jemal A, Schymura MJ, Lansdorp-Vogelaar I, Seeff LC, et al: Annual report to the nation on the status of cancer, 1975-2006, featuring colorectal cancer trends and impact of interventions (risk factors, screening, and treatment) to reduce future rates. Cancer 116: 544-573, 2010.

4. Fang YJ, Wu XJ, Zhao Q, Li LR, Lu ZH, Ding PR, Zhang RX, Kong LH, Wang FL, Lin JZ, et al: Hospital-based colorectal cancer survival trend of different tumor locations from 1960s to 2000s. PLoS One 8: e73528, 2013.

5. Carmen Figueroa-Aldariz M, Castañeda-Patlán MC, Santoyo-Ramos P, Zentella A and Robles-Flores M: Protein phosphatase $2 \mathrm{~A}$ is essential to maintain active Wnt signaling and its Abeta tumor suppressor subunit is not expressed in colon cancer cells. Mol Carcinog 54: 1430-1441, 2015.

6. Perrotti D and Neviani P: Protein phosphatase 2A: A target for anticancer therapy. Lancet Oncol 14: e229-e238, 2013.

7. Ohama T: Targeting PP2A inhibitors as a novel anti-cancer strategy] Nihon Yakurigaku Zasshi 145: 293-298, 2015 (In Japanese).

8. Coles A: Newer therapies for multiple sclerosis. Ann Indian Acad Neurol 18 (Suppl 1): S30-S34, 2015.

9. Gao M, Liu Y, Xiao Y, Han G, Jia L, Wang L, Lei T and Huang Y: Prolonging survival of corneal transplantation by selective sphingosine-1-phosphate receptor 1 agonist. PLoS One 9: e105693, 2014.

10. Jin J, Zhang HJ, Wang XJ, Zhou WQ, Yin DL and Chen XG: Effect of a novel selective S1P1 agonist, Syl948, on mouse skin transplantation. Yao Xue Xue Bao 49: 627-631, 2014 (In Chinese)

11. Brinkmann V: FTY720: Mechanism of action and potential benefit in organ transplantation. Yonsei Med J 45: 991-997, 2004

12. Kovarik JM, Schmouder R, Barilla D, Riviere GJ, Wang Y and Hunt T: Multiple-dose FTY720: Tolerability, pharmacokinetics, and lymphocyte responses in healthy subjects. J Clin Pharmacol 44: 532-537, 2004

13. Rybaczek D, Musiałek MW and Balcerczyk A: Caffeine-induced premature chromosome condensation results in the apoptosislike programmed cell death in root meristems of Vicia faba. PLoS One 10: e0142307, 2015.

14. Van Hoof $\mathrm{C}$ and Goris J: Phosphatases in apoptosis: To be or not to be, PP2A is in the heart of the question. Biochim Biophys Acta 1640: $97-104,2003$

15. Lu Z, Wang J, Zheng T, Liang Y, Yin D, Song R, Pei T, Pan S, Jiang H and Liu L: FTY720 inhibits proliferation and epithelialmesenchymal transition in cholangiocarcinoma by inactivating STAT3 signaling. BMC Cancer 14: 783, 2014.

16. Zhao Y, Guo Q, Chen J, Hu J, Wang S and Sun Y: Role of long non-coding RNA HULC in cell proliferation, apoptosis and tumor metastasis of gastric cancer: A clinical and in vitro investigation. Oncol Rep 31: 358-364, 2014

17. Alinari L, Baiocchi RA and Praetorius-Ibba M: FTY720induced blockage of autophagy enhances anticancer efficacy of milatuzumab in mantle cell lymphoma: Is FTY720 the next autophagy-blocking agent in lymphoma treatment? Autophagy 8: 416-417, 2012

18. Zhang N, Qi Y, Wadham C, Wang L, Warren A, Di W and Xia P. FTY720 induces necrotic cell death and autophagy in ovarian cancer cells: A protective role of autophagy. Autophagy 6 : $1157-1167,2010$

19. Mizushima N, Yoshimori $\mathrm{T}$ and Levine B: Methods in mammalian autophagy research. Cell 140: 313-326, 2010.

20. Kabeya Y, Mizushima N, Ueno T, Yamamoto A, Kirisako T, Noda T, Kominami E, Ohsumi Y and Yoshimori T: LC3, a mammalian homologue of yeast Apg8p, is localized in autophagosome membranes after processing. EMBO J 19: 5720-5728, 2000.

21. Kabeya Y, Mizushima N, Yamamoto A, Oshitani-Okamoto S, Ohsumi Y and Yoshimori T: LC3, GABARAP and GATE16 localize to autophagosomal membrane depending on form-II formation. J Cell Sci 117: 2805-2812, 2004

22. Cristóbal I, Manso R, Rincón R, Caramés C, Senin C, Borrero A, Martínez-Useros J, Rodriguez M, Zazo S, Aguilera O, et al: PP2A inhibition is a common event in colorectal cancer and its restoration using FTY720 shows promising therapeutic potential. Mol Cancer Ther 13: 938-947, 2014
23. Yu HC, Hou DR, Liu CY, Lin CS, Shiau CW, Cheng AL and Chen KF: Cancerous inhibitor of protein phosphatase $2 \mathrm{~A}$ mediates bortezomib-induced autophagy in hepatocellular carcinoma independent of proteasome. PLoS One 8: e55705, 2013.

24. Ahmed D, de Verdier PJ, Ryk C, Lunqe O, Stål P and Flygare J: FTY720 (Fingolimod) sensitizes hepatocellular carcinoma cells to sorafenib-mediated cytotoxicity. Pharmacol Res Perspect 3: e00171, 2015.

25. Estella-Hermoso de Mendoza A,Castello-Cros R,Imbuluzqueta E, Cirauqui C, Pippa R, Odero MD and Blanco-Prieto MJ: Lipid nanosystems enhance the bioavailability and the therapeutic efficacy of FTY720 in acute myeloid leukemia. J Biomed Nanotechnol 11: 691-701, 2015.

26. Hait NC, Avni D, Yamada A, Nagahashi M, Aoyagi T, Aoki H, Dumur CI, Zelenko Z, Gallagher EJ, Leroith D, et al: The phosphorylated prodrug FTY720 is a histone deacetylase inhibitor that reactivates ER $\alpha$ expression and enhances hormonal therapy for breast cancer. Oncogenesis 4: e156, 2015.

27. Cristóbal I, González-Alonso P, Daoud L, Solano E, Torrejón B, Manso R, Madoz-Gúrpide J, Rojo F and García-Foncillas J: Activation of the tumor suppressor PP2A emerges as a potential therapeutic strategy for treating prostate cancer. Mar Drugs 13: 3276-3286, 2015

28. Liu Q, Zhao X, Frissora F, Ma Y, Santhanam R, Jarjoura D, Lehman A, Perrotti D, Chen CS, Dalton JT, et al: FTY720 demonstrates promising preclinical activity for chronic lymphocytic leukemia and lymphoblastic leukemia/lymphoma. Blood 111: 275-284, 2008.

29. Mizushima N and Yoshimori T: How to interpret LC3 immunoblotting. Autophagy 3: 542-545, 2007.

30. Klionsky DJ, Abdalla FC, Abeliovich H, Abraham RT, AcevedoArozena A, Adeli K, Agholme L, Agnello M, Agostinis P, Aguirre-Ghiso JA, et al: Guidelines for the use and interpretation of assays for monitoring autophagy. Autophagy 8: 445-544, 2012.

31. Barth S, Glick D and Macleod KF: Autophagy: Assays and artifacts. J Pathol 221: 117-124, 2010.

32. Kroemer G, Galluzzi L, Vandenabeele P, Abrams J, Alnemri ES, Baehrecke EH, Blagosklonny MV, El-Deiry WS, Golstein P, Green DR, et al; Nomenclature Committee on Cell Death 2009: Classification of cell death: Recommendations of the Nomenclature Committee on Cell Death 2009. Cell Death Differ 16: 3-11, 2009.

33. Gómez VE, Giovannetti E and Peters GJ: Unraveling the complexity of autophagy: Potential therapeutic applications in Pancreatic Ductal Adenocarcinoma. Semin Cancer Biol 35: $11-19,2015$

34. Ozpolat B and Benbrook DM: Targeting autophagy in cancer management - strategies and developments. Cancer Manag Res 7: 291-299, 2015

35. Maiuri MC, Zalckvar E, Kimchi A and Kroemer G: Self-eating and self-killing: Crosstalk between autophagy and apoptosis. Nat Rev Mol Cell Biol 8: 741-752, 2007.

36. Seglen PO and Gordon PB: 3-Methyladenine: Specific inhibitor of autophagic/lysosomal protein degradation in isolated rat hepatocytes. Proc Natl Acad Sci USA 79: 1889-1892, 1982.

37. Böckelman C, Koskensalo S, Hagström J, Lundin M, Ristimäki A and Haglund C: CIP2A overexpression is associated with c-Myc expression in colorectal cancer. Cancer Biol Ther 13: 289-295, 2012.

38. Teng HW, Yang SH, Lin JK, Chen WS, Lin TC, Jiang JK, Yen CC, Li AF, Chen PC, Lan YT, et al: CIP2A is a predictor of poor prognosis in colon cancer. Journal of gastrointestinal surgery 16: 1037-1047, 2012.

39. Ding Y, Wang Y, Ju S, Wu X, Zhu W, Shi F and Mao L: Role of CIP2A in the antitumor effect of bortezomib in colon cancer. Mol Med Rep 10: 387-392, 2014.

40. Zhang N, Wu ZM, McGowan E, Shi J, Hong ZB, Ding CW, Xia P and Di W: Arsenic trioxide and cisplatin synergism increase cytotoxicity in human ovarian cancer cells: therapeutic potential for ovarian cancer. Cancer Sci 100: 2459-2464, 2009. 